for instance, the higher education level-enrollment rate for the wealthiest quintile is almost four times higher than the rate for the poorest. In Argentina, the enrollment rate of the wealthiest is five times higher than the rate for the poorest, and in Mexico the rate is I8 times higher than that of the poorest. In the francophone countries of sub-Saharan Africa, the children of the richest quintile account for 80 percent of higher education enrollment, while those from the poorest 40 percent of the population group represent only 2 percent of the student population.

Enrollments are expanding in gross numbers across the globe, no question, but this massification has happened within privileged groups, not across all socioeconomic groups. Distributing the well-documented and important benefits of higher education to all strata of society will, therefore, remain the most-important challenge for higher education in the decades to come.

\section{The Challenge of Effective Teaching}

\section{ANDRÉs BERnASCON I}

Andrés Bernasconi is professor at the Pontificia Universidad Católica de Chile.E-mail: abernasconi@uc.cl.

For a millennium now, higher education has fostered scholarship and educated people in advanced knowledge. To these core functions others have been added over time, varying in their definition and urgency-such as service to the mission of a church, training civil servants, cementing a national identity, pulling the train of development, spearheading technological innovation, etc. However, teaching and discovery have remained as the essence of the institution we typically associate with the idea of the university and similar centers of higher learning.

Yet, with the reinvention of the university in modern times, research has taken precedence over education as the defining feature of excellence and distinction in this field. True, in the I9th century Humboldtian model, education was to be carried upon the shoulders of the scientific endeavor. Yet, in the age of massification, such virtuous interaction between the activity of research and the environment for learning takes place almost exclusively in the ambit of doctoral training.
Moreover, as academic drift increasingly blurs the research-based definitional line that sets apart universities from nonuniversity tertiary institutions, we see colleges and universities of applied sciences (fachhochschulen) - as well as other institutions that are supposed to have a predominant or exclusive orientation to professional and technical education - veer away from that identity to embrace a research mission, at least in ambition.

Institutional prestige and the personal reputation of faculty are pegged solely to research accomplishments. This association is reinforced today by global rankings, thus the teaching function remains secondary in institutional and professional rewards, attention from the leadership, development of capabilities among the practitioners, and seemingly, in results as well.

This subordination of teaching to research is no longer tenable. For one thing, the overwhelming majority of institutions of higher education around the world carry out no research. For them, the only achievable excellence is of teaching and learning. Next, the minuscule proportion of the world's students who attend the most selective research universities worldwide are generally already quite capable of learning and intellectual development, regardless of the teaching talent of their professors. For the colossal majority of students not attending elite institutions, however, a capable cadre of teachers makes the difference between students dropping out (or graduating, but with minimal learning) versus real mastery of the discipline or the profession that the degree is meant to represent. Moreover, the patience of politicians, with the results achieved by institutions of higher education, seems to be at an all-time low, to judge from the general lack-of-confidence zeitgeist of public policy in the last 30 years, from Britain to Japan to Mexico. Also, this frustration comes not from lackluster research performance, but from poor or unknown effects of higher education over manpower development and productivity.

The time will come when teaching will be open to the same kind of exacting peer scrutiny and judgment as research. Student evaluations will be complemented with expert analysis and feedback over video recordings of classroom, seminar, or laboratory practice. Rewards and recognition will be bestowed upon those who excel in expanding the reach of the minds of their students. 